\title{
LA CUESTIÓN CRIMINAL. ENSAYO DE (RE)DEFINICIÓN
}

\author{
Sergio Tonkonoff \\ Universidad de Buenos Aires - CONICET
}

http://dx.doi.org/10.5209/rev_NOMA.2012.v35.n3.42203

\begin{abstract}
Resumen.- El presente trabajo buscará formular una definición de la cuestión criminal en términos de género próximo y diferencia específica. Ello se hará articulando diversos resultados de la teoría y la investigación social en torno a dos dimensiones constitutivas de dicha cuestión: una sociológica y otra mitológica. El resultado será la conceptualización de las prohibiciones fundamentales como mitos instituyentes de los límites del orden societal, del crimen como transgresión de esas interdicciones, y del castigo penal como un mecanismo de (re)construcción del sistema de clasificaciones básicas de ese orden y la economía afectiva que le corresponde.
\end{abstract}

Palabras clave.- prohibición fundamental, transgresión criminal, castigo penal, dimensión mitológica, dimensión sociológica, dispositivo

\begin{abstract}
This paper seeks to formulate a definition of the criminal question in terms of genus and specific difference. This objective will be accomplished trough the articulation of diverse results of social theory and social research regarding two essential dimensions of this issue: the first, mythological and the second, sociological. The results of this will be the conceptualization of the fundamental prohibitions as founding myths of the ultimate limits of the societal order, crime as a transgression of such interdictions, and criminal punishment as a mechanism of (re)construction of the basic classification system of that order and the affective economy that correspond to it.
\end{abstract}

Keywords.- fundamental prohibition, criminal transgression, criminal punishment, mythological dimension, sociological dimension, devise

He aquí una premisa básica del sentido común sociológico: el crimen es un fenómeno social y como tal está sujeto a las mismas leyes que el resto de los fenómenos de ese tipo. Es este un supuesto compartido por los especialistas en ciencias sociales y el público al que informan, desde que a fines del siglo XIX la escuela craneométrica italiana fuera desplazada del centro del debate científico y político. Entre quienes sostienen tal premisa no existe, sin embargo, un acuerdo sobre lo que ella signifique en realidad. Para que semejante afirmación cobre sentido es preciso saber, ante todo, qué es un fenómeno social. Pero una vez hecho esto, es preciso saber también qué tipo de fenómeno social es el crimen. El primer movimiento, el de su radicación en el mismo terreno en el que tienen lugar la técnica, el arte o la religión, resulta imprescindible para comenzar a comprenderlo - tal es la enseñanza fundamental de la sociología en este punto. Con todo, e independientemente de lo que se crea que es ese terreno común, esta operación de igualación sociológica resultaría insatisfactoria si no fuera completada por el establecimiento de las diferencias específicas existentes entre este fenómeno social y los demás. 
Si, como lo haremos aquí, se postula a lo social como el campo heteróclito de fuerzas colectivas que configuran, movilizan y exceden a los conjuntos societales y a sus miembros -si lo social es la materia que constituye tanto como destituye a la sociedad-, el crimen pertenece a este campo por el modo en el que se produce su definición como acción prohibida, las formas en las que esta acción se actualiza, las motivaciones que la empujan y la manera en que se difunde, así como por las reacciones que provoca. Cada uno de estos elementos forma parte del fenómeno criminal, y aquí buscaremos dar cuenta de ellos. Pero si es cierto, además, que el campo polimorfo de lo social se determina como un orden simbólico sólo a través de un grupo de interdicciones primarias, entonces la cuestión criminal es también, y sobre todo, la cuestión de la producción de los límites últimos de la sociedad - y allí reside su especificidad. Tal es al menos la tesis general que orienta el presente trabajo.

En lo que sigue buscaremos definir al crimen como un fenómeno relacional complejo que implica a) el proceso de producción de prohibiciones primarias o fundamentales, b) su trasgresión por acciones diversamente motivadas, c) las reacciones sociales que frente a ellas tienen lugar, tanto como d) la ejecución de castigos penales. Fenómeno entonces relativo al despliegue de diversas formas de hacer, sentir y pensar que, socializándose, se oponen: aquellas que transformándose en prohibiciones (socio-históricamente) fundamentales configuran las fronteras últimas del orden simbólico, y aquellas que transgreden esos imperativos de exclusión teniendo lugar de manera ocasional o sostenida.

Pero si ciertos actos son calificados como criminales por su oposición a los valores más prestigiosos de un conjunto dado, no por ello ha de creerse que se encuentran impulsados por fuerzas intrínsecamente negativas y carentes de todo sentido social. Veremos que una transgresión criminal es el resultado de afanes y propósitos, opiniones y dogmas que, actualizándose de un modo particular, contradicen preceptos sancionados colectivamente y protegidos penalmente. Se saquea, se hiere, o se mata, por voluntad de riquezas, por odio o amor, por honor o fama: pasiones y convicciones sociales donde las haya. Tanto más sociales cuanto más difundidas y valoradas -y en consecuencia, con más posibilidades de promover la violación de las interdicciones que les dan forma y medida.

Y aún así, veremos también que un crimen se define, además, por su escándalo. Su acontecimiento desestabiliza, inquieta o conmociona, a la vez que seduce con el ejemplo. Suscita, asimismo, un modo de comunicación patético entre quienes lo observan y/o lo padecen, generando lazos afectivos tejidos con el temor, la ira y la indignación -pero también la fascinacióncompartidas. Y siempre da que hablar. Es un germen de conversaciones, rumores y discursos de la más diversa índole. Relatos (morales, jurídicos, científicos, artísticos, periodísticos) que, aún queriéndose veraces, se encuentran siempre habitados de las más resistentes paradojas, cuando no de situaciones y seres imposibles o fantásticos.

Por eso, en lo que sigue, haremos un esfuerzo por diferenciar analíticamente dos dimensiones de la cuestión criminal: una sociológica y otra mítica. El análisis de la primera nos permitirá ver que las acciones prohibidas, aún cuando comporten el ejercicio de la violencia, nada tienen de anti-sociales. La exploración de esta dimensión cumple en revelar el carácter histórico y cultural de las prohibiciones, así como de los comportamientos prohibidos y su 
distribución diferencial, al tiempo que desmistifica la acción criminal y sus actores. Descubre, además, los conflictos de intereses que están en el origen de las regulaciones legales y la selectividad con la que se aplican, mostrando a los sistemas jurídicos y las prácticas institucionales con ellos relacionadas como dispositivos concurrentes en la reproducción de relaciones de producción, poder y propiedad dominantes en un orden societal dado.

Pero si nuestro punto de partida es correcto, los datos resultantes de esta crítica sociológica deben ser completados -o mejor, re-significados- a la luz de aquella otra dimensión que no remite a las prácticas prohibidas en lo que tienen de sociales, ni a los procesos punitivos de generación y mantenimiento de desigualdades socio-económicas, sino a la producción penal de la sociedad como orden simbólico. Esto es, como un conjunto más o menos consistente de sistemas de clasificación o estructuras cognitivas y valorativas que, basados en interdicciones trascendentes, estructuran el campo social y subjetivo en un sentido tanto representacional como afectivo.

Cabe adelantar que ambas dimensiones no se nos presentan como equivalentes. Si es cierto que las prohibiciones fundamentales marcan los límites externos de la sociedad, constituyéndola como "comunidad imaginada", la verdadera cuestión en la cuestión criminal no está principalmente vinculada a la protección de víctimas posibles o al resarcimiento de victimas actuales, ni a la intimidación de infractores potenciales o al castigo de los existentes, como suelen sostener las ideologías jurídicas racionalistas y la doxa ilustrada. Pero tampoco remite exclusiva y aún prioritariamente a la gestión diferencial de los ilegalismos y el consecuente beneficio para la estructura societal en vigor, como proponen las posiciones sociologistas o instrumentalistas. La dimensión más elemental que esta cuestión pone en juego es la construcción y mantenimiento de la estructura lógica y axiológica de la sociedad y de la economía afectiva que le corresponde. Y es este un proceso que opera según una dinámica irremediablemente mitológica.

\section{Prohibición y Sociedad}

Las prohibiciones fundamentales poseen las características generales de cualquier interdicción: rigen como imperativos de exclusión y principios clasificatorios y jerárquicos. ¿Porqué calificarlas entonces de fundamentales? ¿Por el carácter intrínsecamente nocivo de lo que prohíben? Desde una posición post-fundacionalista, es preciso sostener que esa calificación no deriva de su relación con un dominio extra-mundano del que serían una emanación (orden divino), ni por su adecuación a una realidad objetiva e independiente que las antecedería (orden material), sino porque son ellas las que instauran un orden (simbólico) a través de la designación de los reversos radicales del mismo. Siguiendo esta perspectiva estamos obligados a concluir que no hay nada que sea intrínsecamente criminal y que, por esa razón, estaría interdicto. Antes bien, lo contrario es cierto: son estas prohibiciones las que, en cada tiempo y lugar, definen qué deberá ser taxativamente rechazado. Lo que las hace fundamentales o primarias, diferenciándolas de otras que no lo serían, no remite a la cualidad de aquello que condenan sino a la posición estructurante que ocupan. Su fabulosa especificidad reside en designar el 
borde último (o primero) del conjunto societal. Es decir, de lo social simbolizado ${ }^{1}$.

Estas prohibiciones hacen posible las valoraciones, los intercambios y los roles básicos de un orden cultural, por cuanto sus mandatos excluyentes marcan discontinuidades entre el conjunto societal y aquello que será su exterior no complementario. Señalan el umbral más allá del cual no puede seguir hablándose de un nosotros. Elaboran, por así decirlo, el perímetro final del grupo al que de esa manera determinan, separándolo de lo que dejan designado como naturaleza, caos, barbarie. Erigiendo esas fronteras invisibles suturan imaginariamente los contornos discontinuos de la trama social y le devuelven la visión de una totalidad inteligible y consistente, de una sociedad.

Se trata de imperativos de rechazo que se presentan como auto-evidentes. Proscripciones que prescinden de ofrecer alguna explicación: no matarás, no robarás, eso es todo. Pero ese modo de enunciación no las hace menos polares en su estructura: sus condenas implican, por contra, valoraciones positivas (la vida, la propiedad). De esta manera funcionan como máquinas de diferenciación y valorización, a un tiempo clasificatorias y axiológicas. Para quien ve y siente a través de ellas, el ser, el deber y el valer se confunden. Allí reside, tal vez, el núcleo de su eficacia. Su vigencia acaba con la indiferenciación en el mundo y la indiferencia en los individuos. Estas prohibiciones nombran lo que será fundamental, lo recogen y lo separan de una multiplicidad que de otro modo se mantendría indistinta, a la vez que vuelven atractivo su respeto y execrable su vulneración.

Esta dinámica de aversión y seducción remite a otra dimensión cardinal de las prohibiciones primarias: la afectiva. El temor, el vértigo o la turbación producidas por la sola imagen de su transgresión, hablan de lo que puede llamarse su radicación corporal. Es que se trata de interdicciones que funcionan interpelando, constriñendo y direccionado la multitud de deseos de naturaleza mimética y vocación catastrófica que viven en cada cuerpo socializado como impulso y como fantasma ${ }^{2}$. De modo que, internalizadas, obran tanto en la región del pensamiento como en el de las emociones, comprometiendo físicamente a los sujetos de sus proscripciones. Así, el espanto frente determinadas violencias; el asco ante algunos actos sexuales; la culpa, el reproche o la inquietud ligados a ciertas formas de apropiación de los objetos.

Y todavía una tercera característica. Para que una prohibición pueda devenir primaria, es decir, para que tenga el poder de designar los confines del orden societal y subjetivo, es preciso que se vuelva trascendente. Esto puede sólo suceder por la vía de su mitificación. El mito es una forma de articulación del sentido productiva de un campo de visibilidad y de decibilidad, de un esquematismo -pero no a priori sino histórico-cultural- que valoriza la experiencia de manera mucho más emocional que intelectual, que no trabaja con conceptos sino con imágenes apasionadas. De allí que sea acaso el modo

\footnotetext{
${ }^{1}$ Reinterpretando a Durkheim (1993), ha sido Levi-Strauss $(1988,1990)$ quien más ha hecho para establecer el carácter simbólico (diferencial) de todo orden cultural. Lo han seguido en esto Lacan (1975), Barthes (1994) , también Bourdieu (2000) y Alexander (2000)

${ }^{2}$ En este punto las referencias teóricas fundamentales son Freud (1985; 1985a, 1992), Bataille (1974), Lacan (1975) y Girard (1986)
} 
más poderoso de configuración discursiva del mundo. Mediante su narración mítica y, ya lo veremos, mediante su penalización, las prohibiciones van formando cuadros gnoseológicos elementales, grabando profundamente en el deseo de los individuos y los grupos a los que constituye esos "cinco o seis no quiero" de los que hablaba Nietzsche (1997) en su genealogía.

Presentándose como condiciones incondicionadas estas proscripciones devienen verdaderos tabúes, aunque rijan en sociedades presuntamente secularizadas. Cuando se encuentran vigentes de esta forma, sus orígenes se vuelven opacos y sus principios incuestionables (o, al menos, nunca completamente reflexivos) para aquellos que las observan o las transgreden desde dentro. Entonces, el valor negativo de lo que rechazan no precisa demostración alguna $y$, con la fuerza de un fenómeno natural, delimitan distancias insalvables entre acciones a las que postulan como repulsivas y otras que definen por oposición como atractivas. De esta manera se establecen como orígenes de la causalidad y la ley - o como principios de Razón, para decirlo con Legendre (1994) -, haciendo posible la comunicación regular y regulada de las identidades a las que da lugar el espacio significativo que presiden.

Todo esto significa que, en principio, cualquier interdicción puede convertirse en prohibición fundamental y que su institución es política. Pero donde política quiere decir lucha por el establecimiento de los sentidos dominantes y por su encantamiento o sacralización. De manera que aún en nuestras sociedades jurídicamente administradas no basta (y en el límite no sería necesaria) su codificación legal. Imprescindible es, en cambio, su comunicación en un lenguaje fervoroso y su sanción colectiva.

\section{Un fenómeno social}

Desde el punto de vista micro-sociológico, una acción prohibida se diferencia sensiblemente de otra - aún cuando ambas sean nombradas con la misma palabra - si se consideran las mociones a las que responden, si se tiene en cuenta que por debajo de los universales de la ley y la moral transitan los sentidos y los afectos más diversos. Tal vez pueda afirmarse, incluso, que cada nueva motivación crea un crimen nuevo, aunque su tipo mítico (o jurídico) siga siendo el mismo. Es que también los crímenes tienen un alma. Por eso su historia no es sólo la que producen los códigos normativos. Considerada de cerca, esta historia se compone de las cambiantes definiciones de lo prohibido tanto como de los variadísimos impulsos que llevan a su violación.

Permanezcamos en este nivel y preguntemos: ¿de dónde surgen tales motivaciones? ¿es su fuente el individuo? Y ¿cómo esas motivaciones dan lugar a una acción rechazada por las prohibiciones primarias y/o el derecho? En este punto hay que seguir a Tarde $(1952,2011)$ respondiendo que toda acción social es, o bien el producto de creencias y deseos que se imitan de un modelo próximo, o bien el resultado de una invención que tiene lugar como una combinación inédita de series imitativas pre-existentes. No hay diferencia en esto entre el ejercicio - ocasional o sistemático - del robo o el asesinato y el de la ciencia, la industria o la cocina: todas son prácticas cuya presencia en un espacio social determinado hablan de su carácter de creaciones que devinieron 
ejemplos y consiguieron diseminarse, a veces echando raíces, institucionalizándose en alguna medida.

Tal es el caso de la invención, difusión y establecimiento de una religión (Stark, 1997), una técnica agrícola (Katz, 1961), las prisiones correccionales (Foucault, 1989), canciones populares (Sorokin, 1941) o un peinado cualquiera (Deleuze, 2005). Pero es el caso también de la moda de arrojar ácido al rostro del amante traidor frecuentada por mujeres y hombres de finales del siglo XIX, la multiplicación de formas de organización mafiosa durante la crisis de 1930, la práctica de lavado de dinero de agentes financieros internacionales a partir de 1980, la boga de los school shootings en la vuelta del siglo XX. Acciones todas que acontecieron como invenciones una vez y luego se propagaron imitativamente, convirtiéndose en formas de hacer ejemplares - a juzgar por su repetición y permanencia.

Se concederá, tal vez fácilmente, la posibilidad de entender como invenciones la extorsión mafiosa o el lavado de dinero. Un día, se dirá, alguien tuvo la ocurrencia de oficiar como agente de protección extorsiva en áreas donde el Estado era débil o ausente, o de tomar capitales provenientes de actividades ilícitas y llevarlos a producir rendimientos en el mercado financiero. Tal vez se acepte asimismo que, visto el éxito pecuniario obtenido por esos innovadores, esas invenciones, motivadas por la más prosaica codicia, se difundieron ganando émulos interesados en el mismo tipo de rédito. Pero ¿cómo admitir que acciones tan irracionales como desfigurar irremediablemente el aspecto de quien se ama o abrir fuego al azar sobre un contingente de estudiantes puedan tener un origen social? ¿cómo admitir, además, que esos actos terribles y estériles puedan ser imitados del mismo modo que se copian las modas en la pintura, la filosofía o el vestido? ¿Cómo, finalmente, no calificar a su inventor y a sus seguidores de criaturas anti-sociales o aún contra-natura?

Para que ello sea posible sería preciso llevar hasta sus últimas consecuencias lo que habíamos anunciado más arriba. Sería necesario reconocer que lo social es más abundante, más complejo y más contradictorio que la sociedad. Sería necesario admitir igualmente que su dinámica es mimética y que también los individuos son entidades compuestas: soluciones de compromiso permanentemente puestas en juego y en comunicación por corrientes sociales que tanto fundan como desfondan sus identidades. Esta comprensión hace de las personas sujetos de un deseo que siempre es colectivo y que, por lo mismo, puede conducirlas hacia todo tipo de desborde ${ }^{3}$. De ello resulta que cualquier violencia es un asunto social - y más específicamente, permite concebir a la violencia criminal como una de las formas que asume lo social en tanto exceso para el ensamble individual/societal.

Pero hay más. Para admitir esta caracterización del crimen como fenómeno social es preciso aceptar que las innovaciones de cualquier género, grandes o pequeñas, edificantes o destructivas, son siempre el producto del tiempo en el que acontecen, y que ocurren en un individuo o grupo en estado de

3 El concepto clave en esta concepción del sujeto es el de identificación. El tipo de identificación que postulamos vinculada al pasaje al acto prohibido es el que ha sido designado por Lacan (1975, 1975a) como imaginario. Girard (1986; 2010) ha articulado la noción tardeana de mimesis y la noción psicoanalítica de identificación y lo ha hecho precisamente en relación al problema de la violencia. 
desposesión de sí mismo. Es necesario ver que toda innovación (técnica o motivacional) tiene su génesis en la composición o síntesis de premisas socioculturales existentes que se articulan de un modo inédito en un espacio subjetivo al que, por lo mismo, desequilibran. $Y$ esto es válido también para las invenciones criminales, por extraño que parezca. Por eso, más que remitirlas a la anomalía o al cálculo de una mente aislada, es preciso desentrañar las creencias y los deseos colectivos que su acontecimiento (re)presenta combinados de nueva cuenta. Cada nueva acción prohibida no es más que la actualización de una particular mezcla de distintos vectores socio-culturales existentes, o una particular exageración de alguna de ellos. Un crimen suele ser la hipérbole o la combinación bizarra de convicciones y sentimientos muy extendidos y, por ello, no carentes de sentido, si bien puede tratarse de un sentido monstruoso desde el punto de vista societal.

\section{Un fenómeno social estructurado}

Llegado este punto es necesario recordar que las invenciones, las diseminaciones y los establecimientos de comportamientos prohibidos suceden a lo largo de todo el tejido social y no sólo en los ámbitos sobre los cuales existe mayor visibilidad penal y mediática (la pobreza y la marginalidad). Y es necesario añadir que cada sector o grupo tiende a practicar los delitos que le corresponden. En sociedades complejas y desiguales como las nuestras, no sólo las oportunidades legales están societalmente estructuradas ${ }^{4}$. Como todo lo demás, el acceso a los delitos también se encuentra desigualmente distribuido: en el tope de la pirámide socio-económica, las posibilidades ilegales más rentables y con menores riesgos jurídicos y penales; en la base, las más perseguidas y (en general) las menos redituables.

Aunque periódicamente haya excepciones estadísticas, y se cometan delitos "equivocados" en relación a la posición social de sus actores, y aunque cierto tipo de delitos llevados adelante por grupos de extracción popular sean notablemente lucrativos, para comprender la dimensión sociológica de la cuestión criminal es correcto y necesario comenzar distinguiendo entre delitos de los pobres, delitos de las elites, de la burocracia, de las profesiones liberales, etc. Estratificación y especialización que, claro está, no impide la eventualidad de su comunicación transversal y, aún, la emergencia de prácticas delictivas sui generis.

Por otra parte, es posible identificar una serie bien definida de acciones prohibidas en el comienzo de los ordenamientos societales, así como una serie precisa de prácticas ilegales sistemáticas, funcionales a su reproducción. No sólo la agresión militar, el esclavismo y la piratería están vinculadas medularmente a la formación de las naciones modernas (sobre todo, de las más desarrolladas en términos de una economía capitalista). También lo está la expoliación masiva de con-nacionales y su adaptación a esa desposesión "a fuerza de palos, de marcas a fuego y de tormentos" - para decirlo con Marx (1994). Acumulación originaria de tierras, bienes y mercados, y producción violenta de desposeídos que con el tiempo verán su desguarnecimiento como

\footnotetext{
${ }^{4}$ Ver el trabajo pionero de Cloward y Olhin (1960).
} 
natural, pero esta vez "a fuerza de educación, de tradición y de costumbre", para seguir citando a El CapitaP.

$\mathrm{Ha}$ de sumarse a esto el desarrollo de estrategias ilegales como práctica habitual de grupos e individuos en absoluto materialmente necesitados. El fraude, el contrabando, la evasión impositiva, entre otros delitos, suelen formar parte del comportamiento rutinario de actores firmemente establecidos y socialmente prestigiados. Actores individuales y colectivos comprometidos con la lógica básica del modo de producción vigente: minimizar costos y maximizar beneficios.

Agreguemos a este mapa a mano alzada de la distribución de los comportamientos ilegales, toda una extensión dispersa de zonas grises, de vasos comunicantes, donde lo legal y lo ilegal bascula, se conecta y se confunde. En las elites empresariales y financieras, la costumbre del lobby y el soborno, o la absorción institucional de dinero proveniente del tráfico ilegal de armas, drogas o personas; en los sectores populares, los mercados de bienes de consumo apócrifos o derivados de actividades micro-delictivas; en las clases medias, las malversaciones pecuniarias 0 conductas profesionales delincuescentes - por poner sólo algunos ejemplos. En cuanto a la transversalidad de algunas prácticas ilegales, es paradigmático el funcionamiento de la cadena de intercambio establecida entre quienes roban automóviles, quienes los desarman, quienes venden las autopartes, y quienes finalmente las compran.

Resumiendo. Tenemos una multitud de creencias y deseos colectivos discernibles en la raíz de los actos que contradicen las prohibiciones primarias (y/o secundarias), así como el modo mimético de propagación de esos actos y los universos de sentido a los que da lugar su repetición en el tiempo y su establecimiento en el espacio (social), con la consecuente formación de subculturas criminales (o desviadas). Tenemos, además, una multitud de comportamientos ilegales distribuidos por todo el cuerpo social, y una multitud de zonas delincuescentes. Tenemos, también, crímenes fundacionales en los ordenamientos societales vigentes y prácticas fuera de la ley ajustadas al mantenimiento de su orden y su economía. Hay, finalmente, la procedencia ilegal de fortunas y poderes que se incorporan al orden dominante constituyendo, a veces, sus pilares prestigiosos.

Si todo esto fuera correcto, entonces las acciones y las prácticas prohibidas, aún cuando sean violentas, se encuentran muy lejos de constituir un fenómeno anti-social, como míticamente se postula. Antes bien, su cartografía sociológica las deja ver como series dispersas, entramadas en el tejido cotidiano de los distintos grupos según modalidades características. Redes locales, regionales - globales, productivas de configuraciones culturales, a veces, altamente estructuradas. Por eso, desde este punto de vista, tal vez deba calificarse a las acciones y las prácticas criminales no como anti-sociales sino como antisocietales y para-sociales. Esto es, como contrarias a cierta configuración del campo social (aquella que articula el orden simbólico dominante), y como próximas y distantes a la vez de ese corpus del que se nutren - al modo de los parásitos en el organismo o las perversiones en la sexualidad admitida.

\footnotetext{
${ }^{5}$ Sobre la cuestión criminal en Marx ver Melossi (1981) y Taylor, Walton y Young (1975)
} 


\section{Derecho Positivo y Selectividad Punitiva}

Se ve que las prohibiciones, sean primarias o secundarias, no determinan y uniforman directamente ni en igual medida a todas las prácticas sociales; que tales prácticas se distribuyen en un amplio rango de variaciones respecto de ellas (desde la conformidad a las transgresiones sistemáticas). Se ve, en otras palabras, que si las prohibiciones delinean los marcos generales de intelección, valorización y rechazo que (in)forman la interacción social, las acciones y las relaciones sociales refieren a esos contornos actualizándolos, transgrediéndolos o resignificándolos. Agreguemos ahora que esto vale también para las prácticas jurídicas y punitivas de las agencias estatales.

El pensamiento ilustrado ha difundido con éxito la idea de que abolidos los regímenes feudales, míticamente definidos como dominios de la arbitrariedad legislativa y judicial de un príncipe, nuestras sociedades se organizan como regímenes de derecho. Derecho, también él, míticamente comprendido como un conjunto de reglas y procedimientos imparciales que cumplen en representar y defender por igual los intereses de todos los miembros del conjunto. El derecho resulta, en este relato fundante, el conjunto superior y unitario de normas originadas en la razón, desligadas de los afectos intensos, orientadas al bien común y ajenas a las disputas de intereses particulares, que regula el resto de las normas societales (Fitzpatrick, 2000). En el campo de la penalidad, su aplicación se realizaría por medio de un complejo de aparatos administrativos que, obrando sine ira et studio, buscarían detectar todos los actos tipificados por el derecho como prohibidos y castigarlos con vistas a la utilidad social.

Todo esto ha sido severamente cuestionado, al menos desde que Marx (1954) y sus seguidores criticaran la filosofía jurídica de Hegel, poniendo de manifiesto que la dinámica del derecho moderno está íntimamente ligada al desarrollo de relaciones económicas capitalistas, a las que, en gran medida, expresa y favorece. Sucede que de un modo análogo al mercado, la lógica jurídica sólo reconoce individuos abstractos y tiende a reducir las relaciones sociales a la forma del intercambio (abstracto). El derecho penal no escapa a esta operación. También él se articula con base en las categorías reductivas de responsabilidad individual y de igualdad formal ante la ley (Pashukanis, 1985). Presuponiendo como universales realizados el acceso al contrato, la propiedad y el intercambio de bienes y servicios, se ignoran las múltiples determinaciones del comportamiento humano y las consecuencias que sobre éste pudieran tener las desigualdades materiales que el derecho protege y reproduce.

El pensamiento social crítico (y no solamente el marxista) ha llamado la atención, además, sobre las batallas de intereses, tanto sordas como espectaculares, que tienen lugar en las instancias legislativas, por cuanto allí se definen qué acciones u omisiones serán interdictas jurídicamente, volviéndose entonces pasibles de ser legalmente perseguidas y castigadas. Tal instancia resulta de singular valor para el diseño del ordenamiento societal: no tanto por su incidencia directa sobre el destino de los particulares que gozan en tanto tales de los bienes que se ha decidido proteger, como por su participación en la configuración de ese ordenamiento como un sistema de desigualdades sancionado legalmente. Allí se selecciona, del universo de acciones posibles, 
aquellas que serán delito quedando al alcance de actuación de las agencias coercitivas del Estado. Y lo que es tan importante como eso, se determina, por la negativa, cuáles serán los comportamientos que permanecerán libres de tales pretensiones (Sutherland, 1959; Baratta, 2004).

Hay todavía otra instancia, vinculada a la actuación de las agencias punitivas estatales, que constituye un espacio de disputas sociales (más bien sordas), y remite a lo que Foucault (1989) denominó administración diferencial de los ilegalismos. Tal como lo mostrara célebremente este autor, una vez que se ha definido legislativamente cuales son los bienes jurídicos a proteger, los tribunales, la policía y las prisiones actúan a cierta distancia de esas definiciones legales, y más que funcionar como instrumentos del derecho para detectar, procesar y punir todos los actos que éste prohíbe, se revelan como partes de un agenciamiento cuyo objetivo no declarado consiste en separar ilegalismos de delincuencia. Es decir, consiste en intervenir selectivamente sobre la multitud de conductas prohibidas dispersas a lo largo del campo social, disponiendo, por un lado, espacios protegidos para la violación de la ley, y, por otro, zonas donde las infracciones son punidas ${ }^{6}$. Esta distribución corresponde grosso modo a la estructuración societal, desigual en términos de relaciones de producción, poder y propiedad: son perseguidos los ilegalismos populares y tolerados aquellos practicados por los grupos dominantes.

\section{Desmistificación y mito}

Regresemos ahora a aquella premisa básica que habitualmente se da por descontada y que resulta fácilmente aceptable mientras permanezca indefinida: el crimen es un fenómeno social. Para saber qué es lo que esto significa en realidad, resulta necesario tomar ciertas decisiones teóricas e intentar extraer de ellas todas las consecuencias posibles. En lo que a nosotros respecta, hemos optado por una comprensión de lo social como el campo múltiple de creencias y deseos trans-subjetivos que promueven acciones y prácticas igualmente múltiples, algunas de ellas interdictas por prohibiciones primarias y/o secundarias. Luego, hemos caracterizado a las transgresiones como el resultado de corrientes de creencia y deseo que, "realizándose" en una acción, se oponen a esas interdicciones. Finalmente, hemos buscado articular esta comprensión con la crítica sociológica que (de Marx a Foucault) se ha concentrado sobre todo en la tarea de desmistificar la cuestión criminal mostrándola como enlazada a la reproducción del orden societal en sus desigualdades. Resta todavía un paso fundamental.

Sucede que esta crítica sociológica puede ser aceptada sin arribar por ello a las consecuencias más habituales (u ortodoxas) a las que da lugar. Consecuencias vinculadas al supuesto de que dado que las prohibiciones fundamentales, el crimen, el criminal y el derecho son poderosos mitos de la vida cotidiana, y dado que el sistema penal -apoyado en tales mitos- no cumple las funciones que enarbola, entonces esos mitos, los discursos que engendran o penetran, las emociones y los fantasmas que promueven y convocan, las instituciones que crean o invisten, resultan sólo la cáscara que recubre la verdad de un poder/saber punitivo que ya no obraría con tales

\footnotetext{
${ }^{6}$ Sobre la noción de ilegalismo ver Foucault (1989), Deleuze (1987) y Ewald (2000)
} 
instrumentos (Foucault) o de un modo de producción al que sirven de superestructura (marxismo tradicional).

Una valoración diversa de las creencias y los deseos en general, y de los mitos en particular, su ponderación como elementos necesarios para la emergencia y estructuración de las prácticas sociales, permite una visión más comprehensiva de los procesos de producción del orden societal. Pero obliga, además, a una completa redistribución de los resultados alcanzados por la crítica sociológica. Esto es, conduce a articularlos de nueva cuenta al interior de un marco más amplio, resignificando sensiblemente la consideración de lo que sean las prohibiciones, las transgresiones y los castigos penales. Y también, claro está, de lo que sea la institución política de las sociedades, y la política misma.

Sostenemos que los mitos que generan o sostienen prohibiciones no pertenecen propiamente al campo del poder. Son dispositivos simbólicos y lo son de un tipo especial: sistemas de comunicación aptos para convocar los afectos del cuerpo y ligarlos a sentidos últimos o fines trascendentes, y de hacerlo en los propios términos en los que esos afectos trabajan ${ }^{7}$. El poder, en cambio, es el fenómeno social tan instrumental como amorfo del que hablaba Weber (2004) vinculándolo, sobre todo, a la capacidad de coacción de los agentes, y señalando que cualquier situación relacional puede colocar a un individuo o grupo en posición de imponer su voluntad o de soportar las imposiciones de otros. El poder es, entonces, un rasgo ubicuo de la interacción social, sirve a cualquier objetivo y resulta accesible a cualquiera, por eso está marcado por la inestabilidad y el conflicto - Foucault (1987) no lo ha descripto en términos muy distintos. Los mitos, también ellos, son un componente elemental de la vida social, y son omnipresentes en tanto la pasión y la creencia también lo sean. Pero los sentidos míticos nunca resultan totalmente reflexivos y cabalmente instrumentalizables para los actores a los que interpelan. Y si bien se inventan, su eficacia sólo tiene lugar cuando se tornan colectivos e inconscientes. Se trata de relatos narrados según la lógica del pensamiento primario que, socializados ritualmente, proveen de marcos cognitivos intensamente penetrados de afectividad e imaginación. Por eso su fuerza acaso sea la más poderosa y la más duradera: la fuerza de la simbolización apasionada. A través de ellos el poder se estructura y puede estabilizarse, reproducirse y trasmitirse, al tiempo que queda libidinalmente investido y se subjetiviza. Sin ellos, tendría el impacto coercitivo de un golpe, un disparo o un bombardeo (según los casos), pero no podría establecerse y perdurar, convertirse en dominación y autoridad.

Si esto es correcto, es preciso tomar a las representaciones, las fantasías y las emociones colectivas como fuerzas sociales tan insoslayables como vinculantes, y (re)considerar el carácter mítico de la cuestión criminal postradicional en un sentido, por así decirlo, positivo. Porque afirmar que, tras el velo de las ideologías moralizantes, la verdad de dicha cuestión se reduce al accionar de un sistema punitivo que obra en función de intereses materiales y relaciones de poder, imposibilita comprender de manera cabal la persistencia de los elementos valorativos, expresivos y emotivos que ella ineluctablemente comporta y desencadena. Pero impide asimismo conocer los mecanismos a

\footnotetext{
${ }^{7}$ Esta comprensión del mito depende sobre todo de la articulación realizada por Bataille (1974) de los desarrollos de Freud, Cassirer y Levy Bruhl.
} 
través de los cuales el poder de castigar puede transformarse en dominación duradera - que era lo se buscaba explicar en primera instancia cuando desmontaban sus mitos.

Por eso, una vez recorrido el camino de la crítica sociológica es necesario reabsorber sus residuos (ejercicio que, se sabe, siempre termina por reconfigurar el espacio en el que se opera). Un punto de partida para esto puede ser la experiencia del crimen como transgresión. Es decir, en tanto acción prohibida que, no importa cuántas veces haya tenido lugar, resulta siempre aterradora, dolorosa o alarmante para quienes la padecen, la observan - y aún para quienes las realizan. También aquellos abordajes que desestiman esta experiencia por creerla secundaria en relación al problema micro-físico del poder o macro-sociológico de la reproducción económica y la consolidación ideológica de los grupos dominantes, deben dar cuenta de ella. No basta con afirmar que un crimen parece algo terrible, hay que decir por qué lo parece. Buscando una respuesta a esta aparente apariencia tal vez se llegue a la conclusión de que hay muchas falsas razones para postularlo como un acontecimiento amenazador e importante, y algunas verdaderas para suponer que efectivamente lo es. No porque el núcleo de la cuestión criminal tenga que ver sólo, ni fundamentalmente, con la vivencia de los individuos. No se trata de oponer algún psicologismo al sociologismo instrumentalista. Tal experiencia nada tiene de individual. Resulta, más bien, el lugar o el momento donde los individuos son puestos en cuestión por las mismas creencias y deseos que los configuran y los exceden. Experiencia que siempre tiene algo de impersonal, y que adquiere singular relevancia si se entiende a la sociedad como un orden simbólico y a las prohibiciones primarias como los medios de producción de ese orden y sus sujetos.

\section{Un fenómeno desestructurante}

Hemos señalado ya que lo que sea un crimen es siempre relativo al sistema de valores que dominan una cultura en determinado tiempo y lugar. Queda dicho también que ello significa, entre otras cosas, que carece de sustancia intrínseca: al igual que cualquier mal, el crimen depende de la interdicción que lo define. Sin embargo, ni esa falta de esencia ni sus otras características sociológicas le impiden presentarse y ser experimentado, desde el interior del sistema al que transgrede, como un acto reprobable y destructivo. Sociohistóricamente definido, productivo de contagios pasajeros y de estables lazos para-societales, relativamente estructurado desde el punto de vista sociológico, el crimen es desestructurante desde el punto de vista simbólico.

Sucede que si la vigencia de un sistema clasificatorio y una economía afectiva comunes son los requisitos básicos para la existencia y reproducción de las sociedades y sus miembros, la pérdida de las diferencias y el exceso constituyen males radicales. Es transgresor el acto que, en referencia a aquellas clasificaciones y medidas comunes, lleva consigo un principio de indiferenciación y desmesura. Crimen es el nombre que designa las formas extremas de transgresión: aquellas que atraviesan límites reconocidos como fundamentales. Por eso Macbeth, el regicida, dándole palabras a su acción descomunal, declaraba: "añoro que el orbe se confunda". Añoranza que queda cumplida en términos de la experiencia colectiva que el asesinato de un rey 
desencadena. $Y$ esto porque semejante acción representa la cancelación, aunque más no sea momentánea, de la diferencia que sostiene todas las demás diferencias. Siendo el vértice o el centro personificado del sistema socio-político al que su función otorga consistencia, la figura del rey obra como una referencia inconmensurable, sede de valores no intercambiables, que permite los roles y los intercambios posibles en tal sistema. La experiencia de su muerte violenta comporta un shock representacional en los sujetos a ese orden por ser un ataque al núcleo valorativo (o si se quiere al significante amo) que, estando encarnado en él, totaliza el sentido del conjunto social y permite su despliegue regulado. De allí que matar a un rey puede ser el comienzo del fin del mundo.

Terminado el tiempo de las monarquías, emergieron y reinan otros significantes mayores. La vida (del individuo) y la propiedad (privada) rigen, en tanto mitos primarios, el ordenamiento simbólico de las sociedades postradicionales con mano firme y seductora ${ }^{8}$. Por eso las acciones que pongan en juego su integridad trascendente serán transgresiones criminales: atentados a universales vigentes en sus presentaciones particulares 0 , para decirlo con Hegel (1975), negaciones a "lo infinito en el predicado de lo mío". Un crimen es entonces un acontecimiento que amenaza la consistencia de la red sociosimbólica dominante a través de la cual una multiplicidad social en conflicto se produce y se piensa como conjunto. $Y$ dado que estos significantes amos no poseen sólo una dimensión gnoseológica, sino que, además, se encuentran emocionalmente investidos y organizan la economía pasional de los sujetos a su ley, el crimen tiende a producir un desclasamiento cognitivo y una desestabilización afectiva en quienes lo experimentan (como actores, víctimas o espectadores).

De manera que un rasgo característico del crimen es su capacidad de producir la diseminación de un modo de pensamiento vehemente y contagioso, tanto como estados emocionales, y aún valorativos, equívocos - estados que bien pueden llamarse estados de público o de multitud. Este rasgo del fenómeno criminal no parece ser erradicable y, también en las sociedades de la racionalidad jurídica y tecno-científica, debe formar parte de su definición.

Siendo el crimen cognitivamente desestructurante, afectivamente ambiguo, y socialmente multitudinarizante, es preciso conjurarlo: es necesario fijar la ambivalencia que despierta del lado de la repulsión, reinscribir los límites que ha vulnerado, y resituar a los individuos en posiciones de sujetos societales. Tales son algunas de las funciones de la pena.

\section{Castigo (penal) y Sociedad}

Si criminal es el acto que ingresa aquello que el orden simbólico quiso expulsar para cobrar sentido y estabilidad, entonces puede definirse como penal a toda acción punitiva ritualizada que promueva la separación y expulsión de eso que -de acuerdo a las prohibiciones fundamentales- pertenece al exterior. Es penal el castigo que busca (re)establecer las diferencias postuladas por aquellas prohibiciones procurando determinar sus significados y reducir el des-equilibrio

\footnotetext{
${ }^{8}$ Sobre este punto todavía resultan imprescindibles las investigaciones de Durkheim (1989, 2006) y los miembros de L'Anée Sociologique
} 
cognitivo y afectivo producido por el crimen. Se trata pues de un mecanismo que interviene en la producción y re-producción de las fronteras que definen la fisonomía de un conjunto, operando específicamente en el nivel de la institución y el mantenimiento de su sistema axio-lógico y su economía afectiva.

Dicho en otros términos, los castigos penales cumplen en (re)producir, mediante su materialización, las exterioridades radicales que las prohibiciones postulan mitológicamente. Realizan lo que Leach (1993) describió como la condensación ritual de las nociones abstractas que permiten la organización de una cultura. Tal es la función de todo ritual. Pero si los rituales regulares de la vida societal, rituales blancos por así llamarlos, escenifican e inscriben los límites internos del orden simbólico produciendo prácticamente las diferencias y los roles que lo estructuran; los rituales penales, negros o rojos, tienen por misión mostrar y encarnar los límites antagónicos (últimos) de ese mismo ordenamiento.

Se trata de marcar de manera tangible discontinuidades entre un interior societal y un exterior no complementario, entre lo más atractivo y lo más repulsivo - polaridades que definen y mantienen relativamente coherente y unido al conjunto. En nuestras sociedades, ello se realiza personificando o, más bien, individualizando, las acciones (u omisiones) rechazadas por las interdicciones fundamentales. En esto todo castigo penal es ejemplar. Propone a un individuo como portador y como causa del dis-valor que su comportamiento prohibido re-presenta, y lo separa ampulosamente para reconstruir las distancias simbólicas franqueadas por ese acto que las desconoce. Los intereses de los damnificados directos, si los hubiere, tanto como el destino del transgresor son asuntos secundarios respecto del valor lógico del castigo penal. Se castiga penalmente, ante todo, para (re)instituir los espacios conceptuales que dan forma a la sociedad. Toda penalización es, en primer lugar, una elaboración de la noción de límite fundamental tal como la propone el mito. Elaboración que se produce mediante la persecución y estigmatización de individuos y grupos que serán los encargados de presentificar las categorías negativas que, por mor de las prohibiciones, (in)forman la organización y la interacción social.

La codificación mitológica y la puesta en escena dramática son dos mecanismos mayores de la modalidad penal de producción de la sociedad. A través de estos mecanismos, el acto criminal, que bien puede concebirse como la re-emergencia traumática de afectos y sentidos excluidos y en conflicto con el orden dominante, es resignificado en términos de la responsabilidad, enfermedad o maldad de un individuo sólo.

Este proceso de penalización no se limita en absoluto a la acción de las agencias jurídicas del Estado. Antes bien, diferentes instancias de enunciación concurren al montaje de un relato polifónico en el que el criminal resulta una especie de héroe negativo, mísero titán, actor de una violencia que sólo a él (o a ella) le pertenece. Si esta polifonía adquiere un significado definido y comprensible, si los enunciados de los massmedia, por ejemplo, pueden articularse con discursos jurídicos y de la sociedad civil conformando un sentido global, es precisamente porque el mito del crimen como patrimonio del criminal es su principio de unificación (tanto como su campo específico de disputas interpretativas y ejecutivas). En esta mitología, toda acción prohibida es la arbitrariedad violenta procedente de un particular que obra como su único 
dueño y que no sólo no renuncia a su particularidad sino que además la opone a lo universal - conflicto que el orden vigente presenta hegelianamente como bajo la categoría de infinito espurio, falacia lógica y raíz del mal.

Así la transgresión, narrada penalmente, pierde su carácter sintomático. Remitiéndola a un punto de imputación único (el transgresor), se la convierte en un desgarro siempre ya remediado. El modelo mitológico de la penalidad no es trágico sino dramático. No representa un conflicto relacional producido en un conjunto plural y conflictivo que da lugar a un hecho del que tal vez todos y nadie sean responsables. Antes bien, la exhibe como una contradicción superada, por cuanto el umbral de indeterminación, la apertura real que trae al ensamble societal, resulta desmentida por un orden que relatándola míticamente se produce a sí mismo como universal - como infinito verdadero. De esta forma, el carácter social del crimen y su consecuente sesgo de indecidibilidad se ven desconocidos. Y lo que podría ser visto como irremediable encuentra remedio en el juego dramático de los personajes penales y en la participación pública (o mejor, multitudinaria) que promueve.

Es que para completar su eficacia mitológica, la pena misma debe ubicarse en el plano del desequilibrio tendencial producido por la transgresión y, hablando el idioma de las pasiones, debe acerar en el crisol de la multitud los principios que representa. La pena es siempre un llamado a la afirmación exaltada de creencias, deseos e intereses que, mediante una sanción - en el doble sentido de castigo y asentimiento - en común, se instituyen o se confirman como fundamentos trascendentes de un orden. La pena comunica en el lenguaje de los afectos imperiosos y los sentidos fundantes, y su puesta en escena tiene siempre el sentido de la convocatoria a una violencia colectiva - aún cuando dicha violencia deba ejercerse, precisamente, por representación. Sólo de esta manera "hace comunidad", es decir, concurre a transformar una multiplicidad conflictiva (lo social) en una totalidad imaginaria (la sociedad).

\section{El Alma de la Pena}

Proponemos reservar el nombre de penal a toda práctica (institucionalizada o no) tendiente a la producción encarnada del mal mediante la puesta en escena dramática de la transgresión y su castigo. Puesta que, además, lleva siempre consigo conatos de linchamiento y de espectáculo, no importa cuán racional y templada se presente en sus declaraciones oficiales. Hay pena entonces sólo cuando la sanción comporta un acto colectivo de excreción destinada a establecer una alteridad contra la cual los sujetos a un orden societal pueden reconocerse en la conformación de un conjunto moral.

Por cuanto (re)afirma valores y jerarquías en los que una multiplicidad social se reconoce y se delimita, la pena comunaliza. Es decir, produce cohesiones e identificaciones en función de determinados principios clasificatorios; unifica afectiva y axiológicamente a la vez que otorga títulos de pertenencia. Donde había un ensamble societal de individuos, la pena da lugar a colectivos fusionales comunicados en la afirmación de valores que, por lo mismo, se vuelven trascendentes. La operación penal radica en producir (negativamente) esa sacralidad de un modo que evoca siempre un acto plebiscitario. Es una convocatoria a la creencia y la indignación en común y a la satisfacción violenta. Si los miembros del agregado societal son puestos "fuera de sí", si se 
fusionan afectivamente respondiendo a esa convocatoria de rechazo, el bien particular cuestionado por el acto transgresor adquiere el carácter de un bien común. Penalizar un valor es la operación de sustraerlo al intercambio profano, impedir su total instrumentalización, borrando a la vez la huella de su particularidad e impidiendo su puesta en cuestión.

La propiedad privada, por ejemplo, funciona como valor de uso en el cotidiano societal y como valor de cambio en el mercado, al tiempo que, por estar desigualmente distribuida, es también una fuente real o potencial de conflictos sociales. Ahora bien, protegiéndola a través del llamado a su defensa colectiva, los dispositivos mítico-penales la convierten, además, en un valor de sacrificio ${ }^{9}$. Es decir, transforman la propiedad en un principio trascendente que exige ser respetado sin más y que, en compensación, se ofrece como sostén del mutuo reconocimiento y la cohesión grupal. Sacrificándose a él, y sacrificando a los transgresores de su ley, los propietarios de muy diversas cantidades de bienes y capitales, conforman un nosotros. Conjunto en el que individuos y grupos heterogéneos se reconocen como semejantes por medio del rechazo y la separación de otro/s, ex-comunicándolos, designándolos como incompatibles.

Este todos contra uno multitudinario forma parte de la definición del castigo cuando es penal. Pero además, ese mismo movimiento colectivo tiene un valor catártico. La pena constituye, todavía hoy, un interludio festivo donde los pensamientos y las emociones habitualmente contenidas por respeto a la ley y las costumbres, las opiniones y los afectos biliares producidos por las renuncias debidas al establecimiento y la duración del orden, pueden encontrar una vía de compensación y alivio ${ }^{10}$. Descompresión tanto más liberadora cuanto más postergada ha estado su manifestación. Es penal el castigo cuando hace del transgresor un objeto de efusiones íntimas que de otro modo no hallarían posibilidad de expresarse (o que, de hacerlo, traerían difíciles consecuencias). El dramatismo penal tiene por objetivo principal la transformación de los individuos en espectadores, en audiencias a las que busca imprimir cuadros valorativos y a las que permite un doble juego proyectivo: pueden identificarse con la trasgresión representada en las narraciones que la hacen pública, gozar de ella por la persona interpuesta del criminal, y, acto seguido, condenarla moralmente y clamar por su castigo con toda "la fuerza de la ley". De este modo, aún la más burocrática administración de justicia, puede habilitar las proyecciones de una turba imprecisa cuyos miembros obtienen beneficios tanto de la acción prohibida del condenado como de su sufrimiento. Dicha administración puede entonces ganar legitimidad (o fortalecerla) por medio del plus-de-goce que permite y/o que promueve.

Este teatro de la crueldad, tiene pues un sentido económico definido: la pena es un dispositivo mediante el cual las agresiones, la concupiscencia, la codicia - tanto como los rencores y los odios de clase o de status - que no pueden actuarse por temor a las consecuencias que comportan, se purgan y, en la misma operación, se tornan trascendentes y repulsivos (es decir, nefastos). Gracias ese mecanismo penal, anfibio entre lo social y lo societal, la violencia inmanente del deseo, la carga de afectos contenidos que se agita en cada

\footnotetext{
${ }^{9}$ La expresión es de Mead (1997)

${ }^{10}$ La dimensión expiatoria y catártica del castigo penal ha sido explorada por Nietzsche (2002), Alexander y Staubb (1935), Sartre (2002) y Girard (1986).
} 
quien, puede transformarse en exterioridad temida, y la tentación convertirse en repugnancia. Mediante este mecanismo, la negatividad indefinida que mina toda forma social y subjetiva se singulariza y se encarna en un objeto exterior. Cristaliza en un individuo o grupo sobre el cual es lícito exhibir en detalle el acto prohibido en lo que tiene de fascinante, para luego ostentar el odio y el desprecio que, procedente de diversas fuentes, difícilmente halle otra ocasión para manifestarse funcionalmente. Doble ganancia.

En las sociedades modernas y tardo-modernas, más acá de la gestión tecnológica del campo social (sea ésta jurídica, anátomo o bío-política), la dinámica fusional y linchadora de la pena tiene lugar periódicamente. No pocas veces individuos de razón instrumental y la legalidad burocrática han devenido masas justicieras - tanto como masas políticas, guerreras o festivas. De Le Bon (1986) a Sartre (2002) y a Canetti (1977) se ha querido dar cuenta de esta inesperada aptitud para la violencia infamante y sumaria de cualquier ciudadano honrado cuando se reúne con otros en el fervor de una masa. Los pequeños poblados y los vecindarios, pero también los emplazamientos más concurridos y anónimos de las ciudades, se convierten, de tanto en tanto, en la cruz o la hoguera de transgresores execrados en común. No ha de creerse, sin embargo, que esta forma penal de sociabilidad comunitaria tiene lugar sólo en presencia de masas urbanas o de estilos de vida provincianos. En los conjuntos postradicionales ella aparece, sobre todo, en el tipo de asociación que les es característica y que se muestra tan excretante como la comunidad territorial o la multitud reunida: los públicos. El público es un colectivo difuso emancipado tanto de la localidad y sus vecinos como de la ciudad y sus muchedumbres reunidas: una multitud de espectadores, toda hecha de afectos fluctuantes y pensamiento primario, comunicada en el miedo o la alegría, la esperanza o la consternación. En las sociedades del mercado de capitales, tierras y trabajo, la pena se alimenta de la vida de estas comunidades noterritoriales, tanto como las produce. $Y$ de hecho, los públicos constituyen uno de los elementos fundamentales de todo dispositivo penal.

Dispositivo que entonces no debe verse como circunscripto exclusivamente a las instancias especializadas de la administración estatal (fuero jurídico, policía, sistema penitenciario), sino que se conforma cuando estas instancias se enlazan entre sí por la vía del discurso mitológico, entrando en composición con multitudes presenciales o difusas, así como con los medios de producción de tales multitudes (partidos políticos, organizaciones sociales, televisión, radio, prensa escrita, etc.). De modo que el monopolio administrativo estatal del ius puniendi no debe llevar a engaños: la pena es un mecanismo compuesto que excede el marco estatal, y lo hace por la vía de la comunicación multitudinarizante. Cuando en las sociedades occidentales el castigo se volvió, por así decirlo, foucaultiano; cuando su ejecución abandonó la plaza pública y se ocultó tras los muros de las instituciones correccionales, este tipo de comunicación se mantuvo en las salas de los juzgados, los debates parlamentarios y los massmedia.

\section{Gestión Punitiva y Pena / Delito y Crimen}

Todo orden socio-simbólico, por ser un sistema de diferencias y exclusiones se encuentra permanentemente amenazado por aquello que su institución ha 
convertido en exterior radical. Y ello sucede tanto desde el punto de vista representacional y afectivo como práctico. Por eso necesita mecanismos que realicen la (re)inscripción de sus límites a través del doble trabajo de (re)afirmación del sistema de diferencias y de direccionamiento de las fuerzas que lo conforman y lo exceden. Tal es el rol de los dispositivos penales. $O$ mejor, de los distintos agentes sociales (institucionalizados o no) cuando se disponen o ensamblan en el cumplimiento de la función penal ${ }^{11}$. Esto significa que, en sus prácticas, las distintas instituciones y agencias jurídicas estatales pueden o no disponerse de este modo, y que esta disposición siempre es parcial y discontinua. Es decir, que no se encuentran siempre y en todo lugar ensambladas penalmente - pudiendo, cuando no lo están, cumplir funciones sociológicas o permanecer tanto a-funcionales como dis-funcionales en ambos respectos. Significa, asimismo, que estos ensamblajes pueden constituirse aún cuando alguno de los componentes mencionados no entren en la composición, que están abiertos a incluir nuevos elementos, y que habitualmente lo hacen.

Tales dispositivos resultan esenciales en la producción de la multiplicidad social como orden simbólico, aún cuando puedan ser ineficaces en la reducción de los comportamientos reprobados y en la captura y tratamiento (incluyente 0 excluyente) de los transgresores. $Y$ es que, como vimos, el objeto de la intervención penal no es la represión de los actos prohibidos legalmente tanto como la producción mítico-ritual del crimen como mal socialmente definido e individualizado. Mal que, puesto en forma, será lo contrario de la sociedad, y podrá cumplir, además, diversas funciones sociológicas.

Pero todo esto significa que la definición de lo que sea criminal $-y$ sus opuestos- depende de la lucha política en las instancias de su institución (mítica) y en las de su penalización. Y que nunca deja de estar sujeta a permanentes disputas interpretativas y ejecutivas en ambos niveles. En otros términos: la cuestión criminal, tal como se presenta en una cultura determinada, es pasible de todo tipo de estrategización, torsión, y aún de subversión, por parte de los distintos actores sociales. La institución de prohibiciones fundamentales y la acción cierta de los dispositivos penales -esto es, qué tipo de comportamiento será efectivamente criminalizado, y a quienes se perseguirá para que lo encarnen- se encuentra siempre sobredeterminada por las diversas fuerzas sociales que concurren en el intento de interpretarlas tanto como de utilizarlas en su favor.

La obtención o la protección de beneficios económicos, la diferenciación y prestigio social, la defensa de tradiciones o innovaciones, la conservación de privilegios o acceso a ellos, se cuentan entre los diversos objetivos estratégicos que estas luchas pueden poseer. Pero, con mayor o menor grado de inconsciencia, estos objetivos siempre encuentran en la mito-lógica penal un medio mayor de eficacia política. Es decir, de establecimiento de la diferencia

\footnotetext{
${ }^{11}$ La noción de dispositivo se ha dado a conocer de la mano de desarrollos foucaultianos que, por lo general, no coinciden con la perspectiva aquí desarrollada. Sin embargo, su origen en la sociología de Tarde resulta un buen aval para el tratamiento que hacemos de ella. Este concepto tiene la ventaja de evitar las aporías funcionalistas en las que se ve inmerso el tratamiento durkheimniano de la pena, al tiempo que permite conservar muchos de los elementos centrales de dicho tratamiento. En breve: permite dar cuenta tanto de la reproducción del orden simbólico como de su institución política.
} 
buscada como una regla estable y respetuosamente naturalizada de estructuración del campo social.

En las sociedades tradicionales, las costumbres y la religión fueron el (con)texto de estas disputas por el sentido de las penalidades. En las sociedades postradicionales, el derecho ocupa una posición clave respecto del conjunto de los sistemas simbólicos con capacidad de organizar la trama social. Pero si lo antedicho es correcto, esa capacidad no derivaría de su acción técnico-racional (weberiana) tanto como de su posición mítica de ficción sacralizada y sacralizante. Es decir, por cuanto es socialmente imaginado no como código administrativo sino como tercero imparcial, rector autónomo, equitativito, desinteresado, coherente y des-sacralizado (!) de las relaciones sociales. Su eficacia (simbólica) depende de que sus principios y acciones se muevan en el terreno de lo ya común, o de que comunalicen el lazo societal construyendo espacios simbólicos nuevos. Sólo así participa el derecho moderno del dispositivo penal. De otro modo sus textos son letra muerta o se transforman en la cobertura de controles infra-jurídicos de las conductas cuando no funcionan directamente como reglamentos operativos de ese control. Podrá entonces servir, en manos de distintas agencias, para someter individuos y grupos, o para usufructuar y encubrir beneficios desiguales, pero no para producir orden perdurable.

Puestas las cosas de este modo, corresponde distinguir analíticamente entre crímenes y delitos. Los primeros son tipos míticos, los segundos son tipos jurídicos. Unos refieren a las prohibiciones fundamentales y a su transgresión; los otros a las reglas jurídicas y su infracción, omisión o desconocimiento. Por medio esta distinción, no sólo podremos ver lo que parece evidente: que hay acciones delictivas que son criminales. Podremos dar cuenta, además, de la existencia de delitos no criminales, así como concebir crímenes no tipificados jurídicamente. Sabremos distinguir, por otra parte, entre prácticas administrativas o gestionarias del castigo y prácticas penales propiamente dichas, y nos encontraremos en condiciones de establecer vínculos entre ambas.

\section{Bibliografía}

Alexander Franz \& Staubb Hugo (1935). El Delincuente y sus Jueces. Nueva España, Madrid.

Alexander, Jeffrey (2000). Sociología Cultural. Formas de Clasificación en las Sociedades Complejas. Anthropos, Barcelona.

Baratta, Alessandro (2004). Criminología Critica y Critica del Derecho Penal, Siglo XXI, México.

Bataille, Georges (1974). Obras Escogidas. Barral Editores, Barcelona. 
Barthes, Roland (1994). La Aventura Semiológica.Planeta, Buenos Aires.

Bourdieu, Pierre (2000). Poder, Derecho y Clases Sociales. Desclée, Bilbao.

Canetti, Elias (1977). Masa y Poder. Muchnick, Barcelona.

Cloward, Richard \& Ohlin, Lloyd (1960). Delinquency and Opportunity. Free Press, New York.

Deleuze, Gilles (2005). Derrames. Cactus, Buenos Aires.

Deleuze, Gilles (1987). Foucault. Paidós, Buenos Aires.

Durkheim, Émile (1989). La División del Trabajo Social. Alianza, Madrid.

Durkheim, Émile (2006). Lecciones de Sociología. Comares, Granada.

Durkheim, Émile (1993). Las Formas Elementales de la Vida Religiosa. Alianza, Madrid.

Ewald, François. (2000). Foucault. A norma e o direito. Fonseca, Lisboa.

Freud, Sigmund (1985). Tótem y Tabú. Alianza, Madrid.

Freud, Sigmund (1985a). Psicología de Masas y Análisis del Yo. Alianza, Madrid.

Freud, Sigmund (1992). El Malestar de la Cultura. Alianza, Buenos Aires.

Fitzpatrick, Peter (2000). La Mitologia del Derecho Moderno. Siglo XXI, México.

Foucault, Michel (1989). Vigilar y castigar. Nacimiento de la prisión. Siglo XXI, México.

Foucault, Michel (1987). Historia de la Sexualidad. Tomo I. Siglo XXI, México.

Girard, René. (1986). La Violencia y lo Sagrado. Anagrama, Barcelona.

Girard, René. (2010) Clausewitz en los Extremos. Katz, Madrid.

Hegel, G. W. Friedrich (1975). Principios de la Filosofía del Derecho, Sudamericana, Buenos Aires.

Katz, Elihu (1961). "The Social Itinerary of Technical Change" en Human Organization, (verano): 70-82.

Lacan, Jacques. (1975) Escritos 1, Siglo XXI, México.

Lacan, Jacques. (1975a). De la psychose paranoïaque dans ses rapports avec la personnalité suivi de premiers écrits sur la paranoïa. Seuil, Paris.

Le Bon, Gustave (1986). Psicología de Masas. Morata, Madrid.

Leach, Edmund (1993). Cultura y Comunicación. Siglo XXI, Madrid.

Legendre, Pierre (1994). El Crimen del Cabo Lortie. Siglo XXI, México.

Levi-Strauss, Claude (1990). Antropología Estructural. Siglo XXI, Madrid.

Lévi-Strauss, Claude (1988). El Pensamiento Salvaje, Fondo de Cultura Económica, México.

Marx, Karl (1954). Crítica de la Filosofía del Derecho de Hegel. Claridad, Buenos Aires.

Marx, Karl (1994). El Capital, Tomo I, Fondo de Cultura Económica, México. 
Mead, Georges (1997). "Psicología de la Justicia Punitiva". Delito y Sociedad (invierno): 121-142

Melossi, Dario (1981). 'The Penal Question in Capital'. En Crime and Social Justice, Anthony Platt (ed.), 26-33, MacMillan, London.

Nietzsche, Friedrich (1997). La Genealogía de la Moral. Alianza, Madrid.

Pashukanis, Evgeny (1985). La Teoría General del Derecho y el Marxismo.

Grijalbo, Barcelona.

Sartre, Jean Paul (2002). Saint Genet. Ator e Martir. Vozes, Petrópolis.

Stark, Rodney (1997). The Rise of Christianity. Harper Collins, New York.

Sorokin, Pitirim (1941). Social and Cultural Mobility. Free Press, New York.

Sutherland, Edwin (1959). Principles of Criminology. Lippincott, Chicago.

Tarde, Gabriel. (1952). Filosofía Penal. Moderna, Madrid.

Tarde, Gabriel (2011). Sociología Criminal y Derecho Penal. Ad Hoc, Buenos Aires.

Taylor I., Walton P. \& Young J (1975). Critical Criminology. Routledge, London.

Weber, Max (2004). Economía y Sociedad, Fondo de Cultura Económica, México. 